\title{
El Desafío de la Educación en UNA SOCIEDAD DEMOCRÁtICA*
}

\section{The Challenge of Education in a Democratic Society}

\author{
Mónica Llaña Mena \\ Especialista en Investigación Cualitativa \\ Universidad de Chile \\ Ignacia Carrera Pinto 1045, Santiago, Chile \\ mllana@uhcile.cl
}

Recibido: 18 de octubre, 2007. Aceptado: 25 de octubre, 2007

Resumen: La escuela contemporánea enfrenta inéditos desafíos. Asume inesperadas tensiones y debe resolver conflictos que impiden la consecución de sus fines potenciadores del desarrollo humano. Por ello, se sostiene en el texto la urgencia de fortalecer en los procesos formadores, las ciencias de la educación que apoyen en las nuevas generaciones de profesores, la comprensión de la compleja realidad en que se insertan los sistemas educativos en la sociedad contemporánea. Comprensión que los lleve a articular marcos teóricos multidisciplinarios con la acción educativa en aula. Es decir, lograr la recurrente e indispensable conexión teoría-práctica.

En ese marco se analizan las profundas transformaciones socioculturales que constituyen el gran desafío para la educación y que afectan a sus actores principales: profesores y alumnos. Estos actores, al otorgar significados opuestos a su experiencia educativa, alimentan tensiones y conflictos que impiden el logro de una imprescindible y real equidad.

Palabras clave: Escuela democrática, procesos de socialización, centros de socialización, habitus, cultura docente, cultura juvenil.

Abstract: The contemporary school faces new challenges. Unexpected tensions are assumed, and conflicts which hinder the attainment of ends with potential to impel human development must be solved. Therefore, it is sustained here the urgency to strengthen in the formative processes the sciences of education that will favor -in the new generation of teachers- the understanding of the complex reality in which the educational systems are inserted, in the contemporary society. Such understanding will lead them to articulate multidisciplinary theoretical frames with action in the classroom. That is to say, to reach a recurrent and indispensable connection: theory-practice.

This is the frame in which the profound sociocultural transformations are analyzed; they constitute the great challenge for education and they affect their main actors: teachers and students. These actors, when giving meanings opposite 
to their educative experience feed such tensions and conflicts which hinder the accomplishment of an imperative and actual equity.

Keywords: Democratic schools, socialization processes, centers of socialization, habitus, teaching culture, youngsters' culture.

\section{INTRODUCCIÓN}

La concepción de escuela democrática, legitimada en muchos de los discursos oficiales, se afirma con la intención de superar las desigualdades sociales pero negando las complejidades del mundo social y cultural. En otras palabras, opera a través de la reducción de la realidad en la cual se sustentan los sistemas educativos, de manera simplista y unidimensional. Al sostenerse básicamente en la ideología del sentido común, dichas complejidades se sustentan en el ámbito de lo invisible.

Es difícil superar las desigualdades si se niega el contexto histórico, el complejo de relaciones que se entremezclan en determinados espacios sociales y simbólicos y en los cuales los sujetos se insertan, ya adscritos a diferentes capitales culturales.

Indicadores como tasas de deserción, analfabetismo, resultados de pruebas estandarizadas y otros, utilizados recurrentemente para evaluar la eficiencia del sistema escolar, ocultan no sólo la complejidad de las prácticas escolares, sino que la complejidad de las relaciones que se establecen en el espacio educativo y sociocultural.

Desde esta perspectiva, se alude más bien a la productividad del sistema escolar, reduciendo los fines de la educación a "la medida tecnocrática del rendimiento escolar". (Bourdieu y Passeron, 2001).

Desde esta lógica, el sistema educativo, debería responder de manera funcional a las demandas del mercado laboral. Por lo tanto, el sistema más eficiente sería aquel que formará al menor costo y con un alto nivel de eficacia a las personas que la sociedad del conocimiento requiere.

Para ello debe contar con personal especializado en el manejo de estrategias pedagógicas adecuadas, sin requerir de una mayor competencia profesional en áreas disciplinarias consideradas débiles, es decir, las llamadas ciencias "blandas". Y son precisamente las ciencias de la educación, cuyo desarrollo disciplinario reviste el carácter de urgente, las que deberían apoyar a los educadores, para poder develar, comprender, y desarrollar su acción 
pedagógica ante situaciones como diferencias étnicas, de clase, de género, especialmente relevantes en una sociedad como la nuestra que ha experimentado un significativo proceso de masificación de la enseñanza. $Y$ que pasa a enfrentar desafíos más complejos que requieren de perspectivas comprensivas, multidisciplinarias para actuar, como señala Giddens (2003), en esos verdaderos contenedores de poder que son las escuelas.

\section{TENSIONES E INCERTIDUMBRES: SU IMPACTO EN LA EDUCACION PARA LA DEMOCRACIA}

La sociedad contemporánea observa un debilitamiento de las instituciones tradicionales, escuela, iglesia, familia, y es esta última -enraizado eje institucional básico de la sociedad humana- la que marca para las nuevas generaciones, las señales de las incertidumbres.

La incorporación masiva de la mujer al campo laboral está impactando de manera estructural las tradicionales asignaciones de roles según género. $\mathrm{Su}$ ubicación exclusiva en los espacios interiores, el mundo doméstico, el hogar, ha dado lugar a su irrupción en los espacios exteriores, el mundo, generando conflictos y tensiones inevitables que trastornan el espacio familiar. Se presenta, por otra parte, una gran heterogeneidad en la estructura básica encargada de la socialización de las nuevas generaciones puesto que se ha incrementado el porcentaje de mujeres, jefas de hogar, de familias uniparentales, de convivencia sucesiva de precaria estabilidad, de separaciones de hecho y otras formas emergentes de estructuras y dinámicas familiares.

La manera en que el mundo que los otros significativos -padres y madres fundamentalmente- filtran a sus hijos, proceso complejo de fuertes aristas afectivas, los lleva casi inexorablemente a asumir una cosmovisión definida, no sólo por la posición social de la familia de adscripción, sino que también por su dinámica interactiva, por su estructura, por la distribución del poder en su interior, por sus valores, normas y, en última instancia, por su visión de mundo.

La pregunta entonces surge inevitable, ¿en qué espacio social y simbólico se están socializando las nuevas generaciones?

En esa perspectiva, el rol socializador de una familia sometida a cambios estructurales, se diluye y la persona vive experiencias que no se coordinan entre si, ni se unifican en un principio integrador. La escuela, los pares, los medios de comunicación masivos y la propia familia, transmiten normas y 
valores muchas veces en oposición; de manera que la constitución de "la personalidad en una sociedad que tiende a organizarse a partir del consumo, no tiene principio de integración" (Touraine, 2001).

La socialización en contextos históricos previos, permitía la constitución de identidades primarias en tiempos y espacios definidos, reconociendo y valorando los significados de las memorias históricas, familiares y sociales; en su lugar, la televisión y la comunicación vía Internet unen tiempo y espacio y difuminan las tradiciones, las normas y los valores culturalmente compartidos por generaciones. En otras palabras, tradicionalmente existía una simetría entre las normas, los valores externos al individuo y su apropiación subjetiva e individual. Esa simetría hoy se ha roto.

Un riesgo y una amenaza para la conformación de identidades en las nuevas generaciones, residiría en que en esta sociedad de masas, el individuo se convierte en un ser de deseo, en una reiterada búsqueda de placer y satisfacciones personales. Se enfrenta a la tentadora posibilidad, presente en los espacios simbólicos, de adherir a valores que legitiman la consecución del placer y a la adaptación de las instituciones a las aspiraciones individuales. (Lipovetsky, 2001).

Los jóvenes se socializan, en estos nuevos escenarios, enfrentando las incertidumbres, deambulando entre subculturas, centrados en el presente, adoptando conductas transgresoras, conformistas o de marginación según sus experiencias y su entorno vital y social. Movidos por lógicas heterogéneas, competir para uno, ganar, sólo yo y no el otro, ser alguien en la sociedad, disfrutar al máximo de la vida, marginándose y sin formular un proyecto de vida, acumulando energías sólo para proyectos futuros, entre otras posibles lógicas que enmarañan las redes de los complejos capitales simbólicos disponibles en un mundo globalizado.

En ese plano cobra especial relevancia la necesidad de generar acciones educativas que desarrollen climas socioafectivos que apoyen un desarrollo cognitivo y afectivo a nivel profundo. El entorno educativo debería favorecer en los estudiantes la toma de conciencia de si mismos, de los otros, del entorno próximo y de todos los espacios de la sociedad red.

La educación como sistema debería asumir que nos encontramos frente a procesos de socialización insertos en sociedades más flexibles, centradas en la información, sociedades del conocimiento y del consumo que generan, en procesos interactivos y atractivos, permanentes nuevas necesidades a satisfacer, ojalá sin demora, y en ese plano los jóvenes son especialmente vulnerables. 
En síntesis, los viejos centros de socialización se han desplazado hacia otros espacios a través de los cuales han canalizado e internalizado estructuras de necesidades diferentes a las compartidas por las generaciones anteriores: centros de diversión, grupos de onda, musicales y otros, que han contribuido a la generación de nuevas formas de expresividad y sensibilidad en los grupos de jóvenes.

La difusión enorme y penetrante de productos y tecnologías de la comunicación de imágenes atractivas, como otras modalidades de producción cultural propias de una cultura de masas, han contribuido a la gestación de nuevas formas de valoración estéticas y también éticas.

Los medios de comunicación, en especial la televisión, han permitido la extensión de estas nuevas pautas culturales originando, dada la segmentación de los mensajes, nuevos guiones, verdaderos circuitos culturales alternos. La música es, a manera de ejemplo, una instancia a través de la cual se socializan conductas colectivas, estilos de participación, lenguaje, pautas de relaciones sociales, gustos que diferencian a jóvenes de adultos y los acercan a los pares.

Investigaciones realizadas (Llaña y Escudero, 2001, 2003, 2005), muestran que los principales elementos que caracterizan a los estudiantes contemporáneos y que es preciso considerar para generar una educación democrática, está en la comprensión de estas nuevas pautas culturales que se proyectan a las problemáticas del sistema escolar, como representaciones conflictivas y autoritarias de dicha realidad, ya que constituyen obstáculos significativos para una educación para la democracia.

Los estudiantes de estas nuevas generaciones visualizan la escuela como un espacio de poder, de directivos y profesores, y desde su propia mirada, como una institución definitivamente poco democrática. Normas que afectan más bien a modas que los unen como grupos étareo, prohibidas en el espacio escolar y sancionadas rigurosamente, son rechazadas y resistidas con una variabilidad de estrategias que tensionan todo tipo de convivencia y que muestran cuan lejos estamos de alcanzar una educación en y para la democracia.

En estos nuevos, inéditos y emergentes contextos, es fácil inferir que tanto la familia como la escuela han ido perdiendo su peso como agencias tradicionales de socialización, viéndose sobrepasadas por otras subculturas que, como universos simbólicos, están generando verdaderas mutaciones culturales, colocando en oposición al mundo juvenil con el mundo adulto y, 
en el sistema escolar, a profesores con alumnos. Tal vez una dimensión relevante a destacar por sus proyecciones educativas, estaría en una mayor liberalización de las relaciones humanas en diferentes planos, afectivos, eróticos, comunicacionales, más directas y abiertas que antaño, más permisivas en especial al interior del grupo familiar.

En otras palabras estaríamos ante la presencia de habitus construidos en nuevas realidades, que explicarían no sólo las maneras de percibir el entorno sino que gustos y formas de interactuar en los espacios sociales.

Estos habitus, estructurados como principios generadores de prácticas distintas y distintivas (Bourdieu y Passeron, 20001), configuran visiones de mundo, universos de significado que se integran en una totalidad simbólica que se experimenta en la vida cotidiana, en la familia, en el grupo de pares, en la escuela, en los espacios de diversión y otros, y que inciden en los comportamientos y actitudes. Son marcos de referencia general en los cuales se inserta la experiencia acumulada, las prácticas recurrentes, opiniones sobre la sociedad, la familia, la educación, la amistad, expectativas presentes y futuras que otorgan un sentido a su existencia como seres humanos.

Las formas de expresar esas opiniones difieren de las estructuras estructuradas del mundo adulto, a pesar de las diferencias según capital económico y social inscritas en el espacio social. Es importante reconocer que dichas diferencias condicionan la adquisición de diferentes capitales culturales, que obviamente impactan la calidad y la equidad de la educación.

El imaginario social que subyace a este ethos cultural inédito como hemos señalado, se manifiesta en lo simbólico a través de heterogéneas prácticas sociales y que en el ámbito educacional distancia a las generaciones, adultosprofesores versus jóvenes-estudiantes, más profundamente, y se instala en las instituciones para influir en todas las instancias.

En ese marco y sus impredecibles impactos, se inscriben los postulados de una educación orientada hacia la democracia.

Las consecuencias de estas múltiples transformaciones que inevitablemente significan un desafío para la educación en sociedades que buscan fortalecer y perfeccionar formas democráticas de convivencia, se expresan de variadas formas, desde repliegues hacia el yo y aislamiento o marginación, hasta formas de resistencia, entre las cuales se puede destacar la emergencia de movimientos estudiantiles con una visión crítica y propuestas de alto poder de reflexión en demanda de una educación para la participación real, equidad y calidad. 
Surge en muchos estudiantes como grupo, la urgencia de coherencia entre una identidad sentida y la asignada socialmente, y desde sus expectativas como sujetos, la presión de una realidad exigente en vertiginosa transformación. Por lo tanto, la educación debería apoyar el desarrollo de la capacidad de unificar expectativas muchas veces contradictorias y entregarles competencias para que adquieran herramientas cognitivas y afectivas que les ayuden a mantener su estabilidad y desarrollar proyectos de vida.

Esta es parte de la complejidad de los retos que enfrentan los sistemas educativos en la sociedad contemporánea, conformada en la dinámica de procesos complejos marcados por los cambios y su constante aceleración.

No es posible ignorar que la identidad construida como ha sido reiteradamente señalado, conforma una identidad que opone generaciones étareas que conviven en el mismo espacio y tiempo, pero cuyo proceso de socialización y mundo sociocultural internalizado fue muy diferente.

A partir de lo expuesto, se puede señalar que el ethos de la postmodernidad se caracteriza por el peso creciente que han adquirido el individualismo, el narcisismo, el hedonismo como valores predominantes de las identidades construidas e internalizadas, en el marco de las contradicciones que generan esferas sociales como la tecnológica-económica y su racionalidad basada en la eficacia, la productividad, tensionadas por exigencias sociales de mayor igualdad y participación.

Como síntesis es posible afirmar que el ethos cultural imprime un sello inédito a la sociedad contemporánea en varias dimensiones, entre ellas:

- La pérdida de preocupación por las tradiciones acumuladas históricamente.

- Crisis de confianza hacia los líderes políticos (apatía, especialmente en las nuevas generaciones).

- Pesimismo ante un futuro percibido como amenazador e inquieto.

- Énfasis en la realización personal y entusiasmo por el conocimiento, en especial el tecnológico.

- Narcisismo traducido como una verdadera mutación antropológica, un nuevo estadio del individualismo, "...perfil inédito del individuo en sus relaciones con él mismo y su cuerpo, con los demás, emancipado de cualquier marco trascendental" (Lipovetsky , 2001).

- Abandono de los grandes sistemas de sentido y fuerte acento en el yo. 
En otras palabras el ethos de la sociedad postmoderna muestra una valoración exagerada del sujeto, en medio de un materialismo exacerbado en sociedades tecnológicas.

En términos globales, se observa una dicotomía entre una economía globalizada y las culturas internalizadas y compartidas por las personas, situación que tendría insospechadas repercusiones en la conformación de la personalidad y en la construcción de las identidades.

Desde la proyección que estos cambios tendrían en los procesos educativos, convendría destacar, por su impacto en la formación de las nuevas generaciones, la desvalorización de la disciplina y su reemplazo por el deseo y su inmediata realización; el esfuerzo pierde importancia, se estimula la dispersión. Esta situación explicaría, entre otros fenómenos, la falta de interés, de atención, estudiantes sobresaturados de informaciones, telespectadores del mundo que se les presenta multifacético y contradictorio.

Las múltiples y disímiles experiencias a que se ven sometidas las nuevas generaciones, entraban la unidad de su personalidad, problema a asumir por la educación si opta por una convivencia democrática, en especial y reafirmando lo ya expuesto, sin dejar de considerar la emergencia de otra agencia de socialización muy potente, los medios de comunicación en un mundo en red, que ofrecen diversos discursos valóricos y formas de vida heterogéneas que otorgan importancia y validez a otras dimensiones de la realidad, de manera masiva y penetrante. Situación que requiere del desarrollo de un pensamiento reflexivo y crítico para mantener una inestable unidad en ese ámbito.

La educación debe comprometerse de acuerdo a los nuevos procesos de personalización que enfrentan los aprendices de esta era -inmersos en escenarios complejos como los enunciados- a favorecer la gestación de proyectos de vida que los conviertan en actores, en ciudadanos capaces de influir, participar y ejercer su ciudadanía como sujetos significativos.

\section{LA EDUCACION Y DEMOCRACIA}

La complejidad de los contextos sucintamente presentados, nos conduce a plantear dimensiones fundamentales a defender por una educación que contribuya a la permanente reconfiguración de la democracia, esto es, a la defensa de la pluralidad y tolerancia frente a una forma unívoca y totalitaria 
de pensar y ser. El ser humano es un ser inacabado en constante interacción con el mundo el que a su vez es producto de su actividad.

Los sistemas educativos tienen la responsabilidad histórica de apoyar la formación de personas en pleno desarrollo, de ayudarlos a sustentar sus proyectos de vida; a que sean apoyados socialmente y que potencien formas de convivencia que signifiquen el respeto al otro y a las inevitables diferencias entre los seres humanos; apoyando valores de solidaridad, participación en el diálogo constructivo, todo ello desde la más temprana inserción en el sistema escolar.

Por ello se hace imprescindible penetrar en la cultura de los profesores, agentes significativos del proceso educativo. Comprendida ésta como un fenómeno complejo, constituye un ámbito de significatividades, un espacio simbólico en que interactúan con su propio capital cultural, en un espacio que los tensiona al llevarlos, en su acción, a la encrucijada de tener que enfrentar las exigencias de un medio social incierto y cambiante, marcado por una creciente complejidad tecnológica y por una pluralidad cultural, expresión recurrente de un mundo globalizado. La paradoja de esta situación la constituye la aún monolítica estructura de la institución educativa, esencialmente burocrática, jerárquica y. por lo mismo conservadora y reacia a los cambios. Los profesores, en ese escenario, aplican estrategias metodológicas que se insertan inevitablemente en interacciones en aula que nunca son homogéneas; por el contrario, si aceptamos las transformaciones socioculturales de un mundo globalizado, podremos comprender que son heterogéneas y de altos niveles de tensión. Deben además compartir estilos de gestión y responsabilidades administrativas, establecer relaciones con pares, directivos y familias de los estudiantes, lo que configura un conjunto de situaciones que deben interpretar, evaluar, y además, ante las cuales decidir profesionalmente cursos de acción, pero que a partir de lo expuesto y de la experiencia acumulada en investigaciones en esta área, les tornan inseguros y muchas veces amenazados.

La cultura docente entonces enmarañada en una totalidad de acciones, representaciones de la realidad escolar, en estrategias pedagógicas específicas, expectativas, rutinas, relaciones interpersonales con una pluralidad de actores, entraña juegos de poder, grupos formales e informales, que es fundamental conocer en profundidad para generar proyectos innovadores que conduzcan a una educación democrática. Es necesario combatir, desde esta comprensión la inercia, la apatía y la peligrosa desvalorización del rol profesional. (Pérez gómez, 1998). 
La carencia de una comprensión profunda de la cultura docente y escolar en general, inhibe todo proceso renovador y democratizador. No basta con poseer diagnósticos profundos de la acción de los sujetos que participan en la institución, sino que es fundamental analizar la estructura organizacional, los estilos de gestión y el clima global presente en ella como una construcción humana permanente.

Otro aspecto importante de abordar para el análisis de las reales posibilidades de construir una educación democrática, reside en la defensa de la autonomía profesional y la profesionalización real y efectiva del rol. Es inquietante la contradicción entre la importancia otorgada a la educación por la sociedad global y la desvalorización que la misma sociedad asigna al rol docente. Nudo tensional complejo que debería abordarse, a nuestro juicio, con una formación de primer nivel que capacite en una conexión siempre actualizada entre la teoría y la práctica, entre la acción y la teoría. Gran desafío, pero imprescindible paso para negar al técnico y reconocer integralmente al profesional.

Un profesional autónomo será capaz de formar seres autónomos, porque posee confianza en sus competencias y capacidades, seguridad en su forma de abordar su acción profesional y porque la estructura organizacional y los estilos de gestión lo reconocen y confían en su desempeño. Para ello la gestión debe ser efectivamente una comunidad de aprendizaje, de reflexión sistemática de la práctica y de la acción en general, pero siempre orientada por la cultura institucional y las subculturas específicas desde una perspectiva sistémica.

Los tiempos aconsejan una reflexión colectiva que conduzca al análisis profundo de las acciones a emprender para encarar los desafíos planteados, entre ellas y de mayor relevancia para el ejercicio del rol docente, llegar a instalar en el comportamiento cotidiano actitudes de respeto al otro, a sus opiniones, de aceptar la divergencia, evitar las tipificaciones negativas o discriminatorias. En síntesis, se espera que los profesores logren evaluar comportamientos y actitudes sin velos ni prejuicios, lo que entraña una visión profesional y multidisciplinaria que los lleve a convertirse en actores significativos en una educación democrática para la democracia.

Proponemos, a manera de sugerencias, capacidades y valores orientados a un comportamiento democrático que podrían ser incorporados al currículo (Romeo y Llaña, 2005): 
- Develar profundamente la visión del otro a objeto de clarificar las demandas presentadas.

- Discutir las razones que provocan los comportamientos colectivos explícitos y ocultos.

- Reconocer las motivaciones que inspiran las acciones comunitarias democráticas y no democráticas.

- Traducir con fidelidad el sentido que involucran los distintos mensajes que respaldan las acciones democráticas a emprender.

Entre las sugerencias propuestas, importa enfatizar la importancia del uso del conocimiento disponible al servicio de una democracia sustentable, por consiguiente, se propone:

- Manejar información sustancial para argumentar fortalezas, oportunidades, debilidades y amenazas que se observan en los contextos a cambiar o por mantener.

- Dialogar con múltiples exponentes de distintas tendencias a objeto de compartir criterios disonantes y consonantes con la propia posición.

- Ofrecer a la comunidad educativa, opciones de mejoramiento de los procesos en que se está comprometido por el bien común.

- Plantear y replantear proposiciones de acuerdo a los contextos desde donde se sitúa.

Complementariamente, se propone el análisis de los ejes que intervienen en un desarrollo democrático, para ello se recomienda:

- Demostrar autonomía en consonancia con la etapa evolutiva del educando, ofreciendo una participación comprometida en acciones comunes.

- Mantener una postura crítica frente a ideas y comportamientos de acuerdo al sentido profundo de los proyectos educativos.

Básicamente, a partir de lo sugerido, importa identificar los principios sustentadores de la democracia, difundir su valor en el marco de la comunidad de pertenencia, a través de ejercicios para la práctica de ella.

Respecto a valores, ejes para una propuesta a este nivel, se sugiere:

- Hacer conciencia de la situación de desventaja de distintas comunidades y personas demostrando proactividad hacia la superación de debilidades y amenazas reconocidas como tales. 
- Manifestar actitudes cooperativas frente a la satisfacción de necesidades de los otros desarrollando empatía activa y el hábito de hacer el bien.

- Expresar consistencia entre pensamiento, palabra y conducta, mantener la reflexión y la prudencia ante cualquier situación que signifique tomar una decisión.

- Tener conciencia de las limitaciones propias y ajenas con propósito de superación o manejo adecuado de ellas.

- Asumirse como responsable de su propio aprendizaje, ser honesto y consistente con lo que se sostiene, sin lesionar a otro gratuitamente.

Si consideráramos las proposiciones sugeridas, y las vinculáramos con la situación actual, no podríamos dejar de manifestar nuestra preocupación. Cabe la pregunta, ¿qué ocurre con una educación democrática para las democracias precarias y en construcción permanente? i.Si de hecho se mantienen las rigurosas planificaciones de la actividad curricular, las puestas en marcha y la evaluación, sin consideración ni menos comprensión de las subculturas de pertenencia y hasta de la opinión de los propios miembros de la comunidad educativa?

Aún, en la mayoría de las escuelas, no se comparten decisiones ni criterios a adoptar o principios subyacentes; los estilos de gestión continúan en la mayoría de las instituciones educativas siendo autoritarios y no hay claridad ni transparencia en las decisiones.

En consecuencia, emergen múltiples urgencias para construir espacios democráticos que favorezcan una educación en consonancia. En primer lugar, no olvidar que la cultura de cada comunidad educativa tiene su dinámica propia, lo que implica cambios, tensiones, resistencias y significados que, como construcciones simbólicas muchas veces disímiles, cruzan el espacio escolar, escenario que por lo tanto todas las decisiones curriculares deben cautelar, para instalarse en ese espacio poseedor de una realidad concreta.

En esa lógica, también se debe involucrar a los estudiantes, otorgándoles la oportunidad de aprender a ser consecuentes con las elecciones sugeridas por ellos, pero dando cuenta de las fortalezas y debilidades inevitables, en el marco de una formación democrática.

La escuela es una agencia pluricultural que debe apoyar el perfeccionamiento permanente de cada miembro de la comunidad, de quienes en el ejercicio de una participación democrática deberán poner al servicio de la unidad educativa sus fortalezas, expresadas en acciones concretas en programas de desarrollo comunitario. 
El pensamiento de Jaime Sarramona (1993) explicita muy claramente los desafíos que la urgencia de los tiempos demanda a la educación para la democracia: "Educar en y para la democracia no se resuelve por el simple hecho de vivir en una estructura política democrática, por el simple hecho de estar en ella. Significa ser agente activo de su realización, implicarse personalmente en ella como marco idóneo para luego conseguir logros personales y de grupo. Educar en y para la democracias significa, por tanto, crear en los medios y centros educativos las condiciones que hacen posible la vivencia y la práctica de los valores que caracterizan a la democracia" (citado en Chile País Solidario, Romeo y Llaña, 2005).

\section{A MANERA DE SINTESIS: ¿QUÉ HACER?}

A los pies del tercer milenio, somos parte del reino de las incertidumbres. De alguna forma intuimos que progreso económico y material no significa necesariamente desarrollo, y que la vida plena e integral pierde espacios en el mundo moderno.

Entre los posibles ejes que alimentan el desencanto está la relativización de la verdad y la esquizofrenia entre discurso y acción que nutren la desconfianza y, por qué no decirlo, la apatía de las generaciones más jóvenes.

Ha sido reiteradamente señalado que los jóvenes deben encontrar sentido a su experiencia como actores sociales, cuando el mundo vive en medio de una coyuntura histórica en que las agencias tradicionales han debilitado su rol socializador, y la escuela ha dejado de constituir el lugar único y legitimado del conocimiento.

Las inacabadas y profundas transformaciones experimentadas por la sociedad actual, han atravesado la sociedad de nuevas experiencias, ante las cuales los sujetos, especialmente los jóvenes, deben encontrar sentido.

Los cambios culturales han generado una mayor libertad individual, la esfera privada se ha desinstitucionalizado ya que de forma progresiva las instituciones modernas se han ido apoderando de las otrora áreas tradicionales de la vida social.

Vivimos una coyuntura histórica en que ni la familia constituye el eje socializador ni la escuela es el único lugar legitimado del conocimiento. 
Hemos insistido en que los jóvenes como grupo de edad necesitan definir sus proyectos de vida, que deben ser apoyados por marcos de condiciones sociales colectivas y favorables, sin embargo, para muchos de los estudiantes que hoy integran nuestras aulas, esos marcos sociales son excluyentes.

Su subjetividad, es decir, el ámbito donde se conforman sus percepciones, motivaciones, representaciones, valores, se torna difícil de aprehender comprensivamente al interior de la complejidad del mundo moderno, considerando además su inserción en una organización burocrática que aún mantiene rasgos tradicionales, como es la escuela.

De acuerdo a la información obtenida de variadas investigaciones (Romeo, 2001; Llaña y Escudero, 2003; Romeo y Llaña, 2005), los jóvenes manifiestan una fuerte necesidad básica de encontrarse con personas en las cuales fiarse, pero carecen de las redes indispensables en una sociedad en la cual el tejido y la forma de la vida cotidiana se reconfiguran recurrentemente, en respuesta a los cambios sociales y culturales de un mundo globalizado.

Nos encontramos, por consiguiente, con otro tipo de identidades, más precarias y flexibles que funden elementos de mundos culturales cambiantes y disímiles. La existencia de grupos de onda o de estilo, por ejemplo, es ilustrativa de los cambios por los que atraviesa la identidad de los jóvenes. Tanto punks como raperos, thrashers y otros, delimitan un territorio, muestran una propuesta estética. Ante las imágenes asimiladas de la sociedad contemporánea con sus estridencias, ruidos, expresiones de violencia, su desarraigo, exteriorizan otros gustos, estilos, lenguaje, actitudes generalmente desafiantes ante el mundo adulto.

Es así como ante nuestro desconcierto vemos profundizarse el abismo entre generaciones y entre culturas juveniles y escolares. Los jóvenes de nuestra época, insertos en otros espacios comunicacionales, en el torbellino de la comunicación e información instantáneas, logran una extraordinaria facilidad para manejarse en la complejidad de las redes informáticas e insertarse en las heterogéneas comunidades virtuales.

Entonces, y en medio de tantas, múltiples y complejas interrogantes, la gran pregunta que agobia a muchos educadores es, ¿a donde va la educación?

Como una forma de aproximarnos a ese laberíntico mundo, creemos fundamental hurgar en sus profundidades, tratando de conocer por qué resisten 
a él sus actores principales y develar el significado que le otorgan, así como sus proyectos, sus utopías.

Pensamos que estamos ante el riesgo de presenciar la incubación, en escuelas y liceos, de formas arcaicas de rebelión, peligrosas, pues al parecer se rebelan contra el sistema sin discursos propositivos, sin organización estructurada ni liderazgo formal, y sin embargo erosionándolo lentamente.

En ese contexto, percibimos que la vieja escuela no es el único lugar de legitimación del saber, ya que múltiples saberes provenientes de los más recónditos espacios del mundo social cultural impactan a los estudiantes. La escuela contemporánea enfrenta inéditos desafíos, debe asumir tensiones inesperadas e intentar resolver conflictos que perturban un siempre precario equilibrio. El reto mayor quizás sea la confrontación entre un viejo profesor competente y un alumno asertivamente empapado de saberes fragmentados y lenguaje críptico.

De allí la importancia estratégica de una escuela capaz de formar en la solidaridad, el respeto al otro, que constituya una agencia de un desarrollo humano pleno e integral.

Es decir, una escuela que potencie el desarrollo humano. Para ello sostenemos que el currículo debe concebirse como facilitador de ese desarrollo, lo que implica que intencional y sistemáticamente contribuya a desarrollar valores democráticos y en perfeccionamiento permanente. Siempre en un clima humanizado, generando ambientes de aprendizaje que potencien la sensibilización en el respeto, en la participación, en la apertura efectiva y coherente a nuevas realidades y desafíos (Romeo, 2001).

Sin embargo, no puede de ninguna forma desvincularse el currículo de la gestión ni ambos de la evaluación participativa, como tampoco obviarse la constante consideración de los contextos tanto a nivel macro como comunitario o propios de la institución educativa misma.

Para el logro de cambios efectivos, es fundamental además que la unidad educativa asuma otras formas de gestión, revirtiendo estructuras burocráticas que entraban las innovaciones, adscritas a una lógica instrumental pero definitivamente fuera de las demandas de los nuevos contextos históricos.

Estos planteamientos involucran dificultades, riesgos y conflictos, pero constituyen un gran y urgente desafío para posicionar los cambios profundos que requiere una educación democrática para la democracia. 
Sostenemos que toda acción en estos marcos nos permitirá acercarnos a la tan anhelada utopía: la equidad, condición ineludible para la regeneración de espacios auténticamente democráticos.

\section{REFERENCIAS BIBLIOGRAFICAS}

Bourdieu, P. y

J. C. Passeron, 2001

La Reproducción. Editorial Popular, Madrid.

Lipovetsky, G., 2001

La era del vacío. Editorial Anagrama, Madrid.

Giddens, A., 2003

La Constitución de la Sociedad. Amorrortu., Buenos Aires.

Gimeno Sacristán, J., 2005 La Educación que aún es posible. Ediciones Morata. Madrid.

Llaña, M. y E. Escudero, 2003

Pérez Gómez, A.I, 1998

Romeo, J., 2001
Alumnos y Profesores: Resonancia de un Desencuentro. Depto. de Educación, Facultad de Ciencias Sociales, Universidad de Chile. EMEGE Comunicaciones

La Cultura Escolar en la Sociedad Neoliberal. Ediciones Morata. Madrid.

La transversalidad en búsqueda de un currículo holístico. En: Estudios Pedagógicos, No 27. Universidad Austral de Chile. 
Romeo, J. y M. Llaña, 2005 Chile ¿ País Solidario? Depto. de Educación, Facultad de Ciencias Sociales, Universidad de Chile.

Sarramona, J., 1993

Savater, F., 2002

Touraine, A, 2001
Como entender y aplicar la democracia en la escuela, CEAC. Barcelona.

Todo pensamiento es un alejamiento de la realidad. En: Docencia , No 5, Santiago de Chile.

¿Podremos vivir juntos?. Fondo de Cultura Económica. México. 